\title{
Analysis on the Trust Game in Second-hand Transection
}

\author{
Yuchen Cui \\ The High School Affiliated to Renmin University of China, Beijing, China
}

\begin{abstract}
In modern society, every one of us is fully aware that trust and credit are the substantial principle that we must own to build up our relationship, networking or individual development from beginning of birth to end of journey. Thus, trust and credit are undoubted basis for our social composition, especially at current stage, where e-commerce or e-trade mode change our traditional way of life significantly. One interesting thing we are witnessing is that, more and more popularity of the online second-hand product market, so how to understand trust game theory properly, with follow-up the rule to implement in this market, is essentially important for both of the buyer and the seller. Herein this article, some real cases' studies from China second hand market will help reader for this purpose illustration. This study contains much of the current study and discoveries of trust game and second-hand transaction market in China. Based on the previous knowledge, the suggestions for both consumers and the second-hand market producers are given.
\end{abstract}

\section{Introduction}

What we may need specially in modern society development, unilateralism or Multilateralism? It is the most popular topic, or maybe an argument. After four decades of development in globally post-Cold War era, Multilateralism has become the fundamental part, no matter on manufacture supply chain, global service, banking and trading, or even the considerable approach in global diplomatic affairs in some particular areas with international dispute. However, no matter of Unilateralism or Multilateralism there might be in the world, the most essential part indeed or behind of such argument, is the trust among of ourselves to build and maintain, as well as the positive or negative result brought from such trust. By reading and learning from this article, there would be something expected to output and introduce the readers about the basic theory of the trust game, some real cases specially in China second hand market, in relation to trust game implementation, as well as what is important to build trust game model and how the steps are moving forward.

\section{Literature Review}

\subsection{Background and Rules of Trust Game}

Accroding to Wikibooks, the Trust Game designed by Berg Et Al. is a choice experiment to measure the degree of trust in economic decision-making.[1] The purpose of the experiment is to prove that trust is primitive means, or without trust, no business neither any transaction are incurred, because trust is the basis to be set-up prior to any economics transaction, however unfortunately, this is not the fundamental part of mainstream economics. The success of this experiment proves that trust first is problematic for the basic assumptions of standard economics, which tends to ignore trust. Like the other game theory in Behaviour Economics (such as Prisoners' Dilemma game and Public Goods Game), cooperation can benefit the players, but selfish and rational players would not cooperate, which is incompatible with the Assumption of Economic Man.

In the Trust Game, players are randomly assigned roles $\mathrm{A}$ and $\mathrm{B}$. A is the first mover and $\mathrm{B}$ is the second mover. A and B is given an initial payoff, which usually to be 10 dollars. The first mover can choose between exit and engage. If the first mover chooses exit then the game ends, without the second mover making a decision, and the payoffs are $(10,10)$. If $\mathrm{A}$ chooses engage, $\mathrm{A}$ can decide privately whether to send $0,1, \ldots, 10$ of his/her bills to $\mathrm{B}$, and $\mathrm{B}$ will be given triple that amount by the experimenter. $\mathrm{B}$ then need to decide whether to send some, all, or none of them back to A, and then the game end. The finally payoff would be the number of money in A and B's hand.

\subsection{Second-hand Market in China}

\subsubsection{Growing Trend of Second-hand Market:} According to Forward-The Economist, China's secondhand idle market has exceeded 700 billion yuan in 2018, with a compound growth rate of more than $40 \%$ in 2014 2018. Based on this growth, it is expected that by 2020 , the domestic second-hand market will reach trillions of dollars. [4] It is obvious that although the increasing rate is

xinwen@rdfz.cn 
consistently fell in recent years, the Second-hand Market

in China is keeping an increasing trend in general.

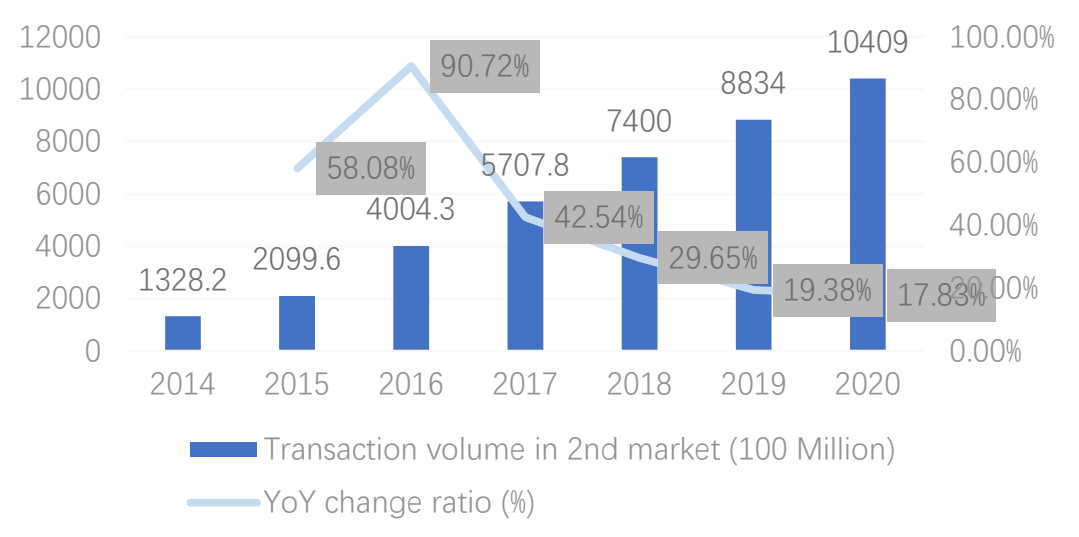

Figure 1. Second-hand Market Transaction value in China (Unit: 10Million Yuan, \%)Different Selling Patterns in Second-hand Market: There are two main modes of platform for second-hand transactions: $\mathrm{C} 2 \mathrm{C}$ and $\mathrm{C} 2 \mathrm{~B} 2 \mathrm{C}$.

The mode $\mathrm{C} 2 \mathrm{C}$ selling by providing a platform to match individual buyers and sellers directly, the two sides negotiate a price to reach a deal. In China, there are platforms like 'Xianyu' and 'Zhuanzhuan'.

However, the $\mathrm{C} 2 \mathrm{C}$ model has risks in the transaction of high-value products(such as used mobile phones) in the following areas:

Time cost:

According to a survey and analysis of Digital in 2017 Global View issued by Accenture, about $62 \%$ of transaction paid by mobile and users believe that "the time and price of the transaction is equally important".

Quality issues:

It would be difficult for buyers to judge with the naked eye whether there are potential quality issues since $\mathrm{C} 2 \mathrm{C}$ transactions are uploaded by individual sellers. Faced with this problem, some platforms introduced the quality checking service, which is like to provide B services in the $\mathrm{C} 2 \mathrm{C}$ model. As the buyer and seller make a deal, the buyer can choose to send the good first to the platform, quality checking will be done by the platform and a report will be send to the buyer. Then buyer and seller will confirm their transaction, and the good will be delivery to buyer from the platform. This effectively reduces quality problems of the goods.

Privacy disclosure:

Some second-hand goods like personal mobile phones often store a large amount of personal information involving privacy issues. So, in transactions without platform protection, information leakage may easily happen.

The mode $\mathrm{C} 2 \mathrm{~B} 2 \mathrm{C}$ was first published by a Chinese platform named 'Zhuanzhuan'. The C2B2C model was designed based on the problems appeared in the model $\mathrm{C} 2 \mathrm{C}$. In the $\mathrm{C} 2 \mathrm{~B} 2 \mathrm{C}$ model, the platform plays a character as a middleman, a second-hand trading trust endorsement and bridge. It means that the platform will take the risk and solve the trusting problems of both sides of the transaction. For the platform, there will be two main characteristics:

Value added service:
The platform need to prepay part of the price for users, then pass the quality checking, re-price the goods with more accurate recovery price as the starting price to enter the second-hand market, where the seller shall get further compensation on top of the advanced payment from the platform, if the final selling result was higher than the market recovery price after the reassessment by platform. Need single standard the quality requirements:

The goods need to pass the quality checking and quality assurance.

\section{Building a game model}

\subsection{Introduction of this model}

In this model, buyer and seller would be regarded as the players. Buyer is the first mover and seller is the second mover. Buyer can choose to buy or not to buy goods from the seller, and the seller can return a same, similar or different good to the buyer. Such would happen in real life while people buying from a $\mathrm{C} 2 \mathrm{C}$ second-hand platform.

\subsection{Buyers' Initial Trust}

3.2.1 The risks for buyers (related to the Trust Game and Economic Person Assumption): The Economic Person Assumption has pretending that people are completely rational and selfish, which means that both side of the game will only care about their benefits. While the sellers only care about their own benefits, they will try to achieve a higher selling price with a lower production cost. In a second-hand market, the production cost is not undertaken by the seller, so the only thing they care about would probably be the selling price.

In order to make a higher selling price, the seller would probably try their best to let the consumer believe that their goods are still new and usable, and it worth the higher price that given by the seller.

Also, most second-hand trading platform has its own shortcomings that sellers will usually set up slogans like 
"second-hand items, do not accept return or exchange", which means that buyers after payment cannot deal with the good they get if they are unsatisfied due to non-human factors.

So, under the assumption of Economic Person, the buyer probably need to take a risk of getting a unsatisfactory or defective products at a higher price.

\subsubsection{Factors influencing the initial trust of buyers:} According to $\mathrm{Lu}$, initial trust is the early and most important stage of trust development. In e-commerce transactions, online merchants are the trusted parties who have the opportunity to grasp the weaknesses of consumers, while consumers are the vulnerable party. In current increasing environment of e-commerce, consumers have encountered many problems of transaction dishonesty, so e-commerce transactions are increasingly cautious. The initial trust of consumers is for an e-commerce initial transaction, and consumers generally can only rely on limited information to determine the level of trust in the seller. [3]

Factors that have an influence on the initial trust of buyers include followings:

Customers' perception:

Great reputation usually need a long time managing, so the reputation of sellers will be an important sign to decide the which seller would be better. In a general way, most of the consumers are more willing to trust those sellers who have a great reputation. This is because buyers consider that these sellers caring more about the buyers' benefit instead of doing opportunistic behaviors. [3]Personal propensity to trust:

Personal propensity to trust in a second-hand transaction shows the personal will of buyers to whether trust or not a particular seller. According to $\mathrm{Lu}$, personal propensity to trust is a relatively stable personality trait, generally not easily affected by other factors. [3] For instance, someone cares a lot about the pictures of the goods given by the sellers, and this would be a personal propensity to trust for them.

\subsection{Sellers' Pay Back}

\subsubsection{Sellers' possible action (related to the Trust} Game and Economic Person Assumption): As the sellers are completely rational and selfish, they would probably not care about either if the consumer will have a good feedback for them, or the consumers' benefit. So, it would be possible that the sellers will do something opportunistic in order to make a greater benefit on themselves.

\subsubsection{Sellers' possible action in real life: As the above} has mentioned that consumers' perception is one of the important determinants of the initial trust, it is impossible for sellers to ignore the feedback from buyers in real life. The reputation of a particular seller will have an influence on the future consumer number of this seller. So, to make a consider in long run, if the seller wants to make sure his/her goods are still welcomed by buyers, reputation should be take into consideration, and that is the reason why most sellers in real life will not give the consumer an unsatisfied transaction experience.

\section{Analysis}

The seller will choose to keep or not keep a good reputation, and the buyer will choose to buy or not to buy goods out of consideration of the seller's credit degree.

Accroding to Yang and Liu, suppose the probability of the buyer buying the goods is P1 and the probability of not buying the goods is 1-p1. The probability of the seller buying in good faith is $\mathrm{P} 2$, and the probability of dishonesty is $1-p 2$. $E$ is the value of the commodity (expressed in terms of price), D1 is the cost of the commodity when the seller conducts business in good faith, and $\mathrm{D} 2$ is the cost of the seller when it conducts business in bad faith (usually D2 \& LT;D1). [5]

TABLE I. MATRIX OF E-COMMERCE SECOND-HAND TRADING PLATFORM [5]

\begin{tabular}{|l|l|l|l|}
\hline & \multicolumn{3}{|c|}{ Seller } \\
\hline \multirow{3}{*}{ Buyer } & & Credit (P2) & No-credit (1-P2) \\
\cline { 2 - 4 } & Purchase (P1) & e, e-d1 & $-\mathrm{e}, \mathrm{e}-\mathrm{d} 2-\mathrm{n}$ \\
\cline { 2 - 4 } & No purchase (1-P1) & $0,-\mathrm{d} 1$ & $0,-\mathrm{d} 2$ \\
\hline
\end{tabular}

When the seller and the buyer make a choice with different probabilities, their expected payoff are also different, and both the buyer and the seller will make the choice that maximizes their expected payoff.

For the buyers, when $2 \mathrm{P} 2-1<0$, then $\mathrm{P} 1=0, \mathrm{U} 1$ is the maximum, which is 0 ; when $2 \mathrm{P} 2-1=0$, then while $0<=\mathrm{P} 1<=1$, $\mathrm{U} 1$ is maximum, which is 0 ; when $2 \mathrm{P} 2-1>0$, then $\mathrm{P} 1=1, \mathrm{U} 1$ is the maximum, which is $-\mathrm{d} 1 \mathrm{P} 2+\mathrm{e} \mathrm{P} 1-\mathrm{n} \mathrm{P} 1-$ $\mathrm{d} 2+\mathrm{n}$ P1P2+d2P2 [5].

For the sellers, when $\mathrm{d} 2-\mathrm{d} 1+\mathrm{nP} 1<0$, thenP $2=0$, U2 is the maximum, which is $(e-n) P 1-d 2$; when $d 2-d 1+n P 1=0$, then $0<=\mathrm{P} 2<=1$, $\mathrm{U} 2$ is maximum, which is (e-n)P1-d2; when $\mathrm{d} 2-\mathrm{d} 1+\mathrm{nP} 1>0$, then $\mathrm{P} 2=1, \mathrm{U} 2$ is the maximum, which is (e-n)P1- $\mathrm{d} 2$ [5].

So, in general speaking, we can see that the probability that a buyer chooses whether or not to buy goods is related to the probability that a seller chooses whether or not to be in good faith, which means that the probability that the seller chooses to keep the promise depends on the magnitude of $\mathrm{d} 1, \mathrm{~d} 2$, and $\mathrm{n}$. While in the real life, the seller integrity transaction is very important for the consumer to protect their legitimate rights and interests, and this is consistent with the results obtained in the model.

\section{Suggestions}

\subsection{Suggestions for Second-hand transaction apps (C2C)}

It would be important for second-hand transaction platforms to make regular survey to get known about their own reputation from users. It would be better for them if they can collect the users' suggestion and improve it on time. Doing so will both increase the number of new users and strengthen the loyalty of older users to the platform. 


\subsection{Suggestions for buyers}

The initial trust from buyers actually cannot be influenced by experience since those transactions may happen discretely. So it is also hard to influence the initial trust from buyers.

\subsection{Suggestions for sellers}

It would be better for sellers if they care more about their second-hand goods. The pictures put online should be as real as possible, and the good should with a proper price. These can help the seller to build a better reputation.

\section{Conclusion}

In conclusion, according to the analysis above, it is obvious that there is a strong connection between trust and the second-hand transaction. At present, many Internet second-hand transaction platforms have taken a series of reasonable and effective measures to facilitate the online credit transactions between buyers and sellers. All kinds of schemes are used, and it forms the credit evaluation system of users and solves the trust problem between users. The second-hand transaction platforms are gradually deal with those trust problems.

\section{Acknowledgement}

First and foremost, I would like to show my deepest gratitude to my teachers in my school and Professor Louis Putterman, who have provided me with valuabe guidance in every stage of the writing of this thesis. Furthermore, I would like to thank all my classmates. Without all their enlightening instruction, I could not have completed my thesis. And I also want to express my thanks to directors from Cetus Talk Online, who give great help to me with my thesis.

\section{References}

1. Brulhart. "Does the trust game measure trust?" Economics Letters 115, no. 1 (2012): 20-23. Doi: http://dx.doi.org.ezproxy1.library.arizona.edu/10.10 16/j.econlet.2011.11.039

2. Lee, S. M., \& Lee, S. J. (2016). Consumers' Initial Trust toward Second-Hand Products in the Electronic Market. joint international conference on information sciences, 85-98.

3. Lu Shengtang. Research on influencing Factors of initial Trust of Fresh E-commerce from the perspective of consumers [J]. Business Economics Research,2020(05):90-93.

4. Wang Siting(2019). Analysis on the current situation and development trend of competition in China's second-hand idle market in 2018. Forward-The Economist. Retrieved from https://www.qianzhan.com/analyst/detail/220/1908 20468e3463.html

5. Yang Yu, Liu Shengyi. Discussion on online Secondhand Trading Platform Credit Based on Game Theory -- Taking Taobao Second-hand trading platform "Xianyu" as an example [J]. Electronic Commerce,2016(08):23-24. 